University of Nebraska - Lincoln

DigitalCommons@University of Nebraska - Lincoln

Papers in the Earth and Atmospheric Sciences Earth and Atmospheric Sciences, Department

\title{
Improving Student Attitudes about Learning Science and Student Scientific Reasoning Skills
}

Douglas K. Duncan

University of Colorado at Boulder, dduncan@colorado.edu

Leilani Arthurs

University of Nebraska-Lincoln, larthurs2@unl.edu

Follow this and additional works at: https://digitalcommons.unl.edu/geosciencefacpub

Part of the Earth Sciences Commons

Duncan, Douglas K. and Arthurs, Leilani, "Improving Student Attitudes about Learning Science and Student Scientific Reasoning Skills" (2012). Papers in the Earth and Atmospheric Sciences. 315. https://digitalcommons.unl.edu/geosciencefacpub/315

This Article is brought to you for free and open access by the Earth and Atmospheric Sciences, Department of at DigitalCommons@University of Nebraska - Lincoln. It has been accepted for inclusion in Papers in the Earth and Atmospheric Sciences by an authorized administrator of DigitalCommons@University of Nebraska - Lincoln. 


\title{
Improving Student Attitudes about Learning Science and Student Scientific Reasoning Skills
}

\author{
Douglas K. Duncan \\ University of Colorado, Boulder, Colorado 80309 \\ Leilani Arthurs \\ University of Colorado, Boulder, Colorado 80309 and University of Nebraska, Lincoln, Nebraska 68588-0340 \\ Received: 10/26/09, Accepted: 08/12/11, Published: 01/24/12
}

(c) 2012 The American Astronomical Society. All rights reserved.

\begin{abstract}
Student attitudes about learning science and student ideas about the nature of science were compared at the end of two astronomy courses taught in Fall 2007, a course with a traditional astronomy curriculum and a transformed course, whose traditional astronomy curriculum was supplemented by an embedded curriculum that explicitly addressed the nature of science and student metacognition (i.e., thinking about one's own thinking.) The embedded curriculum in the transformed course gave students practice at evaluating examples of valid science and pseudoscience found on the internet; it also provided students opportunities to discuss what they think about learning science. Student attitudes and ideas were assessed using the epistemological beliefs assessment for physical science (EBAPS) survey, interviews, and written responses to an open-ended exam question. Our results indicate that the embedded curriculum led the majority of students in the transformed course to think that anyone can learn science, whereas a majority of students in the traditional course thought that only individuals with innate abilities can learn science and think scientifically. Students in the transformed course also reported much more confidence in their ability to evaluate the scientific validity of information found on the internet. Furthermore, students from the transformed course valued making sense of science more than students from the traditional course. The embedded curriculum could readily be used in any course for nonscience majors, not just introductory astronomy.
\end{abstract}

\section{INTRODUCTION AND PREVIOUS WORK}

Many universities have requirements that nonscience majors take at least one science course. The goal is not to turn them into scientists; rather it is to give them a better understanding of how science works, and an understanding of scientific ways of reasoning. A desirable outcome is that students' reasoning abilities improve. At the precollegiate (K-12) level, the National Science Education Standards (1996) indicate that students should understand the nature and practice of science. Understanding how science works and the nature of scientific knowledge has been seen for decades as important to the scientific literacy of the general populace (Miller 1989; Miller 1998). Scientific literacy can no longer be reserved for scientists alone because nonscientist members of our society are and will continue to be confronted with personal and public policy decisions that involve science (e.g., medical treatments for cancer or voting decisions on issues concerning Earth's environment.) This demands a working knowledge of what science is, how scientific knowledge is developed, how to distinguish pseudoscience from valid science, and the limitations of science.

Although crucially important, the nature of science (NOS) is rarely taught or assessed. A potential problem is that there are many definitions of the NOS. We follow Lederman (1992) who states that the NOS refers to the epistemology of science, science as a way of knowing, or the values and beliefs inherent to the development of scientific knowledge. We adopt a pragmatic approach in the current work by concentrating on aspects of the 
NOS agreed upon by a majority of scientists and useful to students (e.g., Lederman 1992; McComas 2004; and Abd-El-Khalick, Waters, Le 2008), particularly the ideas concerning what science is.

Assessing students' views about the NOS is challenging. Forced-choice instruments and open-ended interviews have limitations associated with suitability for a given audience, pertinent depth, and breadth of individual and collective items, and relevant context of and content of the items (Elby et al. 2001, EBAPS home page). Forcedchoice instruments may not enable students to adequately express their own ideas. Open-ended instruments or interviews may require follow-up questions that can potentially lead students toward particular responses [Sandoval, 2003]. However, the goal of many of those who teach science courses to nonscience majors is to improve their scientific reasoning and help them to make better informed decisions about scientific issues. This is a more limited goal than teaching about all potential aspects of the NOS.

An increasing number of teachers, particularly in K-12 levels and in preservice teaching programs, are specifically targeting the NOS through their course curriculum. Strategies that have been implemented for teaching NOS include puzzle-solving activities (Clough 1997), pictorial gestalt switches (Michaels and Bell 2003), activities that require students to make inferences from limited data sets, and an emphasis on the importance of scientific language (e.g., terminology such as law, theory, prove, true) (Clough and Olson 2004). Published examples of similar efforts at the college level (excluding preservice teaching programs) are scarce.

Various efforts have been made to assess students' views about the NOS before and/or after taking traditional science courses. "Traditional" is used here to indicate that the NOS is not explicitly taught as a part of the science course curriculum. A recent study focused on atmospheric science majors at a large research university (Parker et al. 2008). Seventeen juniors and seniors participated in a study where they completed the views of nature of science questionnaire version C (VNOS-C) during the first week of classes; three of these 17 students also consented to be interviewed. Based on their findings, Parker et al. recommended explicit integration of teaching the NOS in atmospheric science undergraduate courses. Another study, by Adams et al. (2006), used the Colorado learning attitudes about science survey (C-LASS) to measure individual changes in student attitudes after taking a traditional physics course as compared with their attitudes at the start of the course. Over 7000 students from 60 different college-level physics courses participated in the study. The C-LASS instrument was used to measure how "expertlike" and "novicelike" students' views about learning science were. Adams et al. found that in every application of the survey to introductory physics classes, the overall class populations became less expertlike in their views about learning science. Their findings support Sandoval's (2003) idea that doing science doesn't necessarily change ideas about science. It has also been shown that students who become more proficient in scientific knowledge (specifically, mechanics or electricity, and magnetism) do not necessarily become more proficient in their scientific reasoning abilities (Bao et al., 2009).

With respect to the field of astronomy, surveys of those who teach introductory college-level astronomy courses indicate that an important learning goal is to increase students' understanding of the nature and process of science (Slater et al., 2001). Most astronomy courses, however, do not explicitly address the NOS through assigned home-work or other activities designed to give students practice thinking about the nature or process of science. They also do not explicitly discuss scientific reasoning. Even astronomy lab activities that are supposed to provide scaled-down examples of doing science rarely ask students to think about and discuss the meaning of what they are doing. Such curricula apparently assume that just by learning astronomy content or doing science activities students will automatically obtain more expertlike ideas about the NOS. The findings of Adams et al. (2006), however, suggest that students do not develop more expertlike views about NOS when NOS is either only implicitly taught or not taught at all; in fact they are likely to develop more novicelike views.

Herein, we discuss the efforts of one college-level astronomy instructor to explicitly teach selected aspects of the NOS that deal with defining what science is, scientific reasoning, and metacognition to nonscience majors enrolled in an introductory level astronomy course. The objective of the present study was to examine the following questions:

(1) What is the status of introductory-level astronomy students' attitudes about learning science and ideas about the nature of science after a semester of traditional astronomy instruction?

(2) What is the status of the same student attitudes and ideas when specific aspects of the NOS, scientific reasoning and judgments, and metacognition are explicitly taught?

Our project studied two introductory courses for nonscience majors taught in fall 2007 at the University of Colorado by two different instructors. Both instructors are highly rated by students and had taught the same 
course more than once. The traditional course covered basic principles of light, motion, and gravity, and applied them to the solar system. The transformed course covered the same basic principles but applied them to stellar and extragalactic astronomy. In the traditional course, the NOS was only implicitly covered during the course of instruction. The transformed course taught by Duncan explicitly discussed specific aspects of the NOS, scientific reasoning, and metacognition using an embedded curriculum (see below), which was added to the traditional astronomy curriculum. Students were explicitly taught what science is and the difference between scientific and other ways of knowing. They were repeatedly asked to make and discuss their own scientific judgments throughout the semester. Students were also regularly engaged in discussions that required them to think about how they think about their own learning in the course and in general.

The traditional course was the first of a 2-course sequence. The transformed course was the second in such a sequence. The courses were not a perfect match since most students in the transformed course had one previous semester of astronomy and were on average one semester older. Otherwise the class demographics were very similar (mostly freshmen and sophomores; comparable numbers of male and female students; class sizes between 150 and 200). Eliciting student participation from these two courses allowed us to collect a sizeable amount of data, including a large number of interviews and classroom observations by Arthurs. We hope that our interesting results will prompt others to try similar experiments in their courses, some of which are more precisely matched. Hereafter, students in the course that received traditional instruction will be referred to as the "Control Class" and the students in the transformed course will be referred to as the "Test Class."

\section{EMBEDDED CURRICULUM}

In order to explicitly teach elements of the NOS and scientific reasoning to his students, Duncan developed a curriculum that was embedded within the traditional astronomy curriculum of his course. The embedded curriculum was driven by four learning goals and executed through activities that stimulated student thought about science (valid science and pseudoscience) and learning science. The activities were implemented under the premise that giving students practice at thinking, reading, writing, and talking about science and their experiences learning science would allow them to develop more expertlike understandings of the NOS and what is involved in learning science. A central question that framed the course was "What is science?" Although the answer to this question can be and is hotly debated by historians of science, philosophers of science, and scientists, for the purposes of this introductory-level astronomy course, students were taught that science is: a process of trying to understand the world by making models (or theories) which have predictive power and that it usually involves observation; finding patterns and trends; posing explanations/hypotheses; iterative processes of data collection, interpretation, and hypothesis testing; and telling others what you have discovered. They were also taught that the practices of testing hypotheses and making data-based predictions distinguish science from other ways of understanding the world such as religion, philosophy, and intuition. One technique Duncan used throughout the course to hook his students into valuing science and wanting to learn science was his regular recitation of Richard Feynman's famous quote, "Science is a way of trying not to fool yourself," to which Duncan also added "or being fooled by others."

\subsection{Learning Goals}

The learning goals of the transformed course included the following. Students will be able to:

(1) Discuss the NOS and specifically discuss the question of "What is science?"

(2) Develop metacognitive skills for learning science.

(3) Distinguish between valid science and pseudoscience (i.e., bogus science).

(4) Recognize how the terms theory, model, and believe differ between scientific and lay contexts.

\subsection{Activities}

To develop students' views about the nature of scientific knowledge and attitudes about learning science, the primary interventions used were weekly explicit in-lecture discussions and periodic take-home assignments. These discussions amounted to $\sim 10 \%$ of the total in-lecture time during the semester. The discussions fell into a few general categories, including what is science, cases of contemporary pseudo/science issues, and personal attitudes about learning science. Given that the class attendance averaged 150 students on any given lecture day, 
these in-lecture discussions were technology-supported. First, powerpoint slides were projected on a large screen that was used to display visual images, graphical data, and pose multiple-choice questions. Then, I $<$ CLICKER software and hardware were used to poll students and collect their responses. Sometimes, students were also asked to discuss their responses with nearby peers. After the polling session, the instructor was able to display the aggregate results of the poll and engage students in a whole-class discussion.

\subsubsection{Cases of Contemporary Pseudo/Science Issues}

Approximately $25 \%$ of the cases discussed were drawn from astronomy and $75 \%$ from other sciences. All involved scenarios that students might encounter in their own lives. Personal relevance was a more important criterion for the selection of cases than was whether the case dealt with astronomy. Part of the teaching strategy was to promote the value of using scientific reasoning to evaluate information in students' own lives. Richard Feynman was once asked to define science and, in response, he said, "Science is a way of trying not to fool yourself." Duncan uses this statement with the addition of "or be fooled by others" in his transformed course as an effective hook for engaging students in learning about NOS_-because no one likes to be fooled. Using cases of personal relevance in these discussions were likely particularly useful to the nonscience majors taking the course because nonscience majors commonly believe that science does not apply to their day-to-day lives (Stempien 2007). Below are examples of actual cases and discussion questions involving contemporary pseudo/science issues:

Example A: (1) Pose the question and have the students vote on: Which vehicle is safer to drive? Simultaneously show photos of each one of the vehicle choices (Toyota Camry, Jeep Cherokee, and Ford F-series pick-up). (2) View I<CLICKER histogram of polling results. (3) Display and discuss data concerning deaths associated with each vehicle type.

Example B: (1) Pose the question and have the students vote on: If you are African-American in the US today, which job are you more likely to have? (a) Sports (playing or coaching) or (b) Science and engineering (including medicine). (2) Ask students to choose from among the following answer choices: (A.) (a) is more likely, (B.) (b) is more likely, (C.) About the same, and (D.) (b) is ten times more likely than (a). (3) View I $<$ CLICKER histogram of polling results. (4) Display and discuss employment data of African Americans.

Example C: (1) Pose the question and have the students vote on: How many people do you think have psychic power or extra-sensory perception? (A) Only a few people, (B) All people do but some have it more than others, and (C) No one has been able to demonstrate such powers in a repeatable way when carefully tested. (2) View I<CLICKER histogram of polling results.(3) Tell a Sherlock Holmes story about being observant. (4) Pose the same question and have the students vote again. (5) View I<CLICKER histogram of new polling results.

\subsubsection{Cases of Personal Attitudes About Learning Science}

Nonscience majors often hold views about learning science that can hinder their ability to learn science (Stempien 2007). Developing a working knowledge of what science is goes hand in hand with the ability to learn science. A part of the embedded curriculum in the transformed astronomy course therefore directly addressed students' views about learning science. An attempt to simultaneously reveal and shape students' attitudes about learning science was also done through explicit technology-supported in-lecture discussions based on specific scenarios. These discussions often led to a return to two metacognitive questions, (a) How do you learn science? and (b) How do you know when you know? Examples of the actual scenarios and discussion questions involving attitudes about learning science include:

Example A: (1) Present Bloom's Taxonomy. (2) Discuss the fact that this class requires students to do more than simply memorize facts.

Example B: (1) Present midterm grade distribution from the previous year. (2) Discuss what is needed to earn a particular grade in the upcoming midterm. Contrast the higher grades of students who participate in peer discussion during class to the lower grades those who just listen.

\subsubsection{Take-Home Assignments}

In addition to the explicit in-lecture discussions about NOS, seven take-home assignments were also designed to be a part of the embedded NOS curriculum. Generally, these assignments required students to read about a case and provide a written response to associated questions. The first student assignment is shown in Figure 1. The readings associated with each assignment often presented surprising data, such as on the safety of different vehicles (e.g., what looks big and safe often isn't) and stereotypes (e.g., what you see in the media often doesn't reflect reality). Discussion of the readings and students' responses to the associated questions emphasized the 


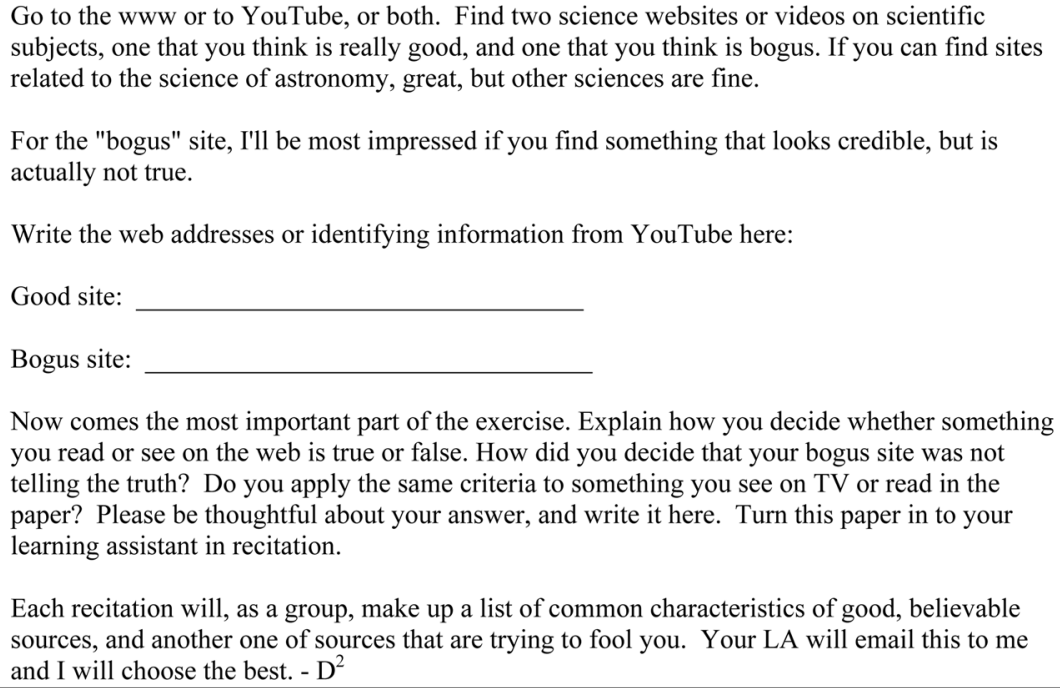

Figure 1. The first "science vs pseudoscience" assignment was given out in the first week of class.

need for actual data rather than a reliance on appearances, anecdotes, or intuition. One reading assignment described a test that showed how astrology works (i.e., it depends on psychology, not astronomy). Two reading assignments involved alien abductions and repressed memory syndrome as examples of how personal experience is not always reliable. Other reading assignments involved so-called psychics, who look impressive on YouTube but are impressively exposed in other videos. Several reading assignments involved medical or health issues and were particularly thought-provoking because students, their family members, and/or their friends had related personal experiences.

Some assignments were deliberately provocative because the goal was to have students recognize that scientific topics can affect their lives in serious ways. For example, when discussing vaccination-refusers (i.e., those who believe vaccines cause autism and refuse to have their children vaccinated) students were shown a photo of a polio ward from the days before polio vaccines. When asked, less than $5 \%$ of the students had ever seen such a photo. When discussing "natural medicines" students are told about the story of a professional baseball player who died from using Ephedra. The baseball player was 23 years old, similar in age to most of the students in the class. Discussion of these examples produced a strong reaction from many students, which provided an optimum opportunity for teaching about NOS in the context of day-to-day realities. All the assignments are available at http://casa.colorado.edu/ dduncan/pseudoscience.

\section{ASSESSMENT}

Three different techniques were used to assess the Control and the Test classes' end-of-semester status of their views about NOS. They were administered a forced-choice instrument called "epistemological beliefs assessment for physical science" (EBAPS), participated in structured interviews to answer open-ended questions about the nature of science and were asked on their final exams whether their class changed the way that they think about science. Acknowledging the aforementioned limitations of these kinds of assessment techniques as well as the difficulty in capturing comprehensive student thoughts about NOS, our objective was to use their combined results to provide a "snapshot" of students' views after having received a semester's worth of traditional and transformed instruction about NOS within the context of an introductory college-level astronomy course.

\subsection{Epistemological Beliefs Assessment for Physical Science}

The EBAPS is a 30-item forced-choice instrument, which was initially developed and validated by Elby et al. (2001) at the University of California at Berkeley. The intended audiences for EBAPS administration are high school and college level students enrolled in physics, chemistry, or physical science courses. The two introductory level astronomy courses involved in this study integrated elements of physics and chemistry throughout the curriculum. Although the EBAPS was not expressly designed for astronomy courses, we thought it could still be a valuable instrument in our study. We were particularly interested in seeing whether any differences emerged between the Control Class and the Test Class in terms of their responses to the subclasses that comprise the EBAPS. These subclasses include: (1) structure of scientific knowledge, (2) nature of knowing and learning, (3) 


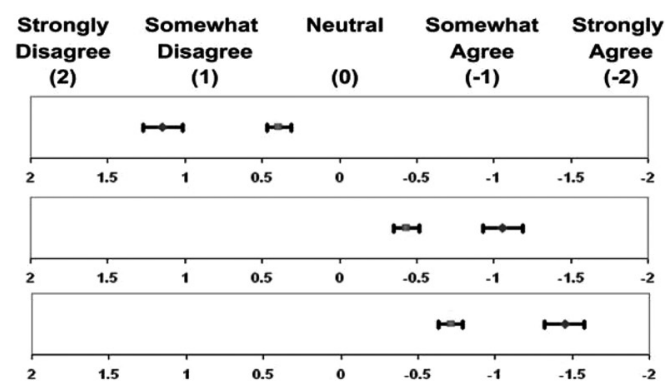

16. Given enough time, almost every
scientifically, if they really wanted to.

22. To be successful at science:

(2 Hard work is much more important than inborn natural ability.

(1) Hard work is a little more important than natural ability.

(0) Natural ability and hard work are equally important.

$(-1)$ Natural ability is a little more important than hard work.

$(-2)$ Natural ability is much more important than hard work.

25. Anna: I just.read about Kay Kinoshita, the phycisist. She sounds naturally brilliant. Emily: Maybe she is. But when it comes to comes to being good at science, hard work is more important than "natural ability." I bet Dr. Kinoshita does well because she has worked really hard. Anna: Well, maybe she did. But let's face it, some people are just smarter at science than other people. Without natural ability, hard work won't get you anywhere in sciencel

(2) I agree almost entirely with Anna.

(1) Although I agree more with Anna, I think Emily makes some good points

(0) I agree (or disagree) equally with Anna and Emily.

(-1) Although I agree more with Emily, I think Anna makes some good points.

$(-2)$ I agree almost entirely with Emily.

30. Jessica and Mia are working on a homework assignment together..

Jessica: O.K., we just got problem \#1. I think we should go on to problem \#2. Mia: No, wait. I think we should try to figure out why the thing takes so long to reach the ground. Jessica: Mia, we know it's the right answer from the back of the book, so what are you worried about? If we didn't understand it, we wouldn't have gotten the right answer. Mia: No, I think it's possible to get the right answer without really understanding what it means. (2) I agree almost entirely with Jessica.

(1) I agree more with Jessica, but I think Mia makes some good points

(0) I agree (or disagree) equally with Mia and Jessica

(-1) I agree more with Mia but I think Jessica makes some good points.

(-2) I agree almost entirely with Mia

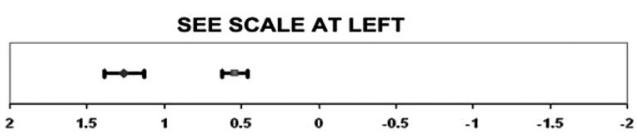

Figure 2. Six EBAPS questions solicited differences in student responses from the Control Class and the Test Class that were statistically significant. Test class: green circles; control class: red squares.

real-life applicability, (4) evolving knowledge, (5) source of ability to learn, and (6) overall NOS. The EBAPS is available at http://www2.physics.umd.edu/ elby/EBAPS/home.htm.

The EBAPS was administered at the end of the semester to students in the Control and Test classes. The Control Class had complete responses from $45 \%$ of students and the Test Class from 56\%. Enrollment in the Control Class was 380 students, in two sections of similar size that were taught separately by the same instructor. The Test Class enrolled 123 students.

Out of the 30 EBAPS questions, six questions produced responses that were statistically different between the Test and Control Classes (Figure 2). For these six questions, the difference between the classes was large ( $>3.5$ $\sigma)$. In terms of the subclasses in the EBAPS, four questions came from subclass 5: source of ability to learn (Q 9, 16, 22, and, 25), 1 question came from subclass 6: overall NOS (Q 4), and one question came from the subclass 2: nature of knowing and learning (Q 30).

We interpret the collective responses to the first five aforementioned questions as an indication of students' ideas about who can do science and the responses to the last question (Q 30) as an indication of the importance that students place on making sense of science. Figure 3 shows a typical example of one of the 6 questions where the responses significantly differed between the classes.

The responses differ substantially, as may be quantified through a chi-square test of the null hypothesis that the two samples could have been drawn from the same population. Table 1 shows the data for both classes as well as the expected data if both samples are summed together and the responses of the five bins taken as the average of the two samples. Chi-squared is equal to the sum of the squared differences between observed and expected, divided by the expected (since the variance in a counting experiment such as this follows a Poisson distribution; $\sigma^{2}=\mathrm{n}_{\text {expected }}$ ).

The reduced Chi-sq for 9 degrees of freedom is 22.2, showing negligible chance that the differences are not real. A Kolmogorov-Smirnov test of the two cumulative distributions produces a difference statistic $\mathrm{D}=0.30$. The 
(a)

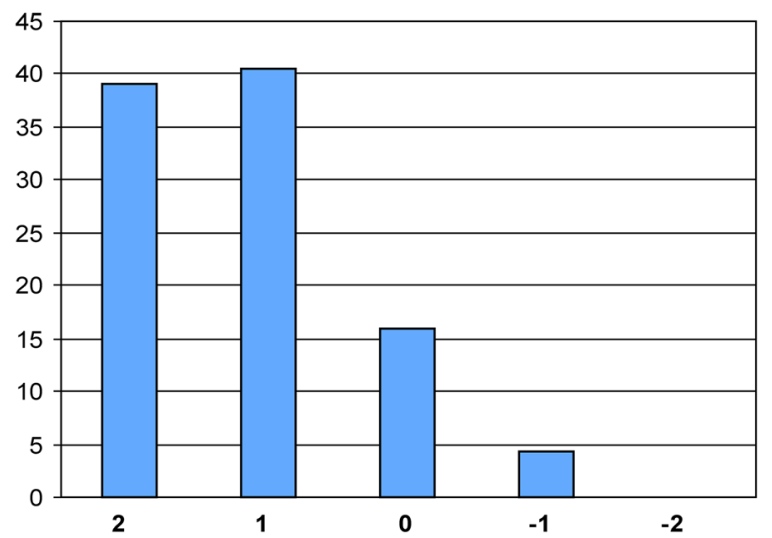

(b)

Control Class

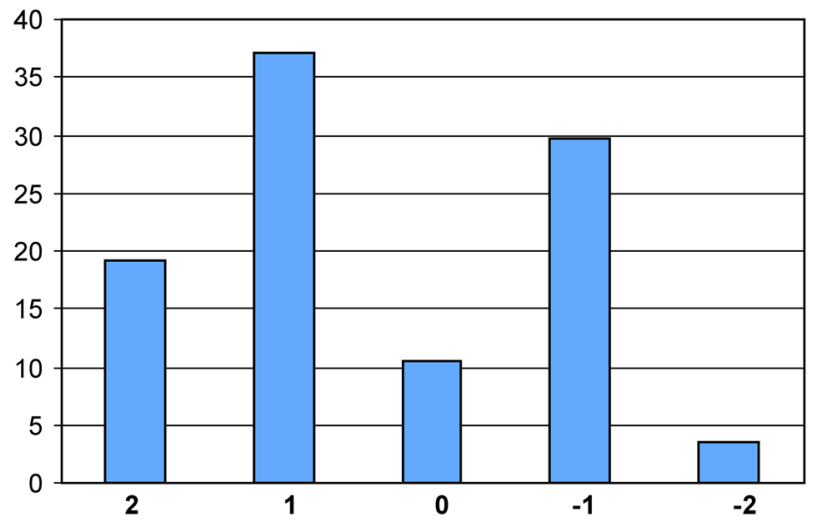

Figure 3. (a) Test Class and (b) Control Class responses to the EBAPS question, "When it comes to science, students either learn quickly, or not at all." On the x-axis, 2 represents "strongly disagree," 1 represents "disagree," 0 is neutral, -1 "agree," and -2 "strongly agree."

corresponding probability is $\mathrm{p}<0.001$ that the difference between the two classes is due to chance. We also compared the classes by forming a single average index for each question in each class:

$$
\text { average response }=2^{*} \mathrm{~N}_{\text {strongly disagree }}+\mathrm{N}_{\text {disagree }}-\mathrm{N}_{\text {agree }}-2^{*} \mathrm{~N}_{\text {strongly agree }} \text {. }
$$

Figure 2 plots this index for the six questions where the classes differ significantly. For the question discussed in Figure 3 , the difference exceeds $4 \sigma$. For all six questions it exceeds $3 \sigma$.

\subsection{Student Interviews}

For the purposes of the overall project interviews were comprised of 9 questions. Five of the nine questions were developed by Duncan, and four were drawn from the "views of nature of science" (VNOS) Questionnaire version C (VNOS-C; Lederman et al. 2002). The VNOS authors suggest that the VNOS-C be administered as a written questionnaire and that the administration be followed up with individual interviews to insure the validity of the instrument. For the purposes of our project, however, we did not ask students for written responses to the selected VNOS-C questions and instead asked the questions during student interviews. The nine interview questions asked are included below. Questions \#1, 6, 7, and 8 were derived from the VNOS-C.

1. What, in your view, is science? What makes science (or a scientific discipline such as physics, biology, etc.) different from other disciplines of inquiry (e.g., religion, philosophy)?

2. What is a scientific theory?

3. What is the scientific method?

4. Does following the scientific method guarantee you will achieve correct results?

5. Does following the scientific method improve your chances of getting correct results?

6. After scientists have developed a theory (e.g., atomic theory), does the theory ever change? If you believe that theories do change, explain why we bother to teach scientific theories. Defend your answer with examples.

7. It is believed that about 65 million years ago the dinosaurs became extinct. Of the hypotheses formulated by scientists to explain the extinction, two enjoy wide support. The first, formulated by one group of scientists, suggests that a huge meteorite hit the earth 65 million years ago and led to a series of events that caused the extinction. The second hypothesis, formulated by another group of scientists, suggests that

Table 1. Percentage responses of the actual data shown in Figure 3, along with expected values if both were drawn from the same population.

Observed values $\quad$ Expected values

\begin{tabular}{llllllclllll}
\hline Test class & 39 & 41 & 16 & 4 & 0 & Test class & 25 & 38 & 12 & 22 & 3 \\
Control class & 19 & 37 & 10 & 30 & 3 & Control class & 25 & 38 & 12 & 22 & 3 \\
\hline
\end{tabular}


massive and violent volcanic eruptions were responsible for the extinction. How are these different conclusions possible if scientists in both groups have access to and use the same set of data to derive their conclusions?

8. Some claim that science is infused with social and cultural values. That is, science reflects the social and political values, philosophical assumptions, and intellectual norms of the culture in which it is practiced. Others claim that science is universal. That is, science transcends national and cultural boundaries and is not affected by social, political, and philosophical values, and intellectual norms of the culture in which it is practiced. If you believe that science reflects social and cultural values, explain why. Defend your answer with examples. If you believe that science is universal, explain why. Defend your answer with examples.

9. Richard Feynman has been quoted as saying, "Science is a way of trying not to fool yourself. What do you think he meant?

The complete results of the interviews will be presented in detail in a future paper. Here, we report on one question: "What is a scientific theory?" (The word scientific was emphasized.) Twenty students from the Control Class and 23 students from the Test Class were interviewed. In addition, nine students who had not yet taken an astronomy course were interviewed. Students were given a small amount of course credit for participating in the interviews, and it was emphasized that students of all levels of ability were desired as subjects. To examine and compare their responses, we developed a 2-category rubric prior to rating student responses for what we considered an expertlike understanding and a novicelike understanding of what a scientific theory is. Responses were categorized as novicelike if they included ideas such as "(just) an idea," "a guess," "an opinion or hypothesis" without mentioning any testing. Responses were categorized as expertlike if they included phrases such as "based on [any of the following] data, evidence, experiment, and/or observations" or "a tested idea." The rubric was intended to reflect the common confusion between a scientific theory and the everyday use of the word theory. Using the rubric to rate student responses, the authors had an initial inter-rater reliability of $89 \%$. All discrepancies in ratings were resolved through discussion. Figure 4 summarizes the findings. They show that no statistically significant difference is observed in the percentages of students in the Control Class and Test Class that hold an expertlike understanding and a novicelike understanding on the single question of what a scientific theory is. Students in both classes have more expertlike understandings of what a scientific theory is compared with students that had not yet studied astronomy. Given that understanding what a scientific theory is is a demonstrated area of deficiency with respect to students' ideas about NOS (Abd-El-Khalick, Waters, Le 2008) and that this is demonstrated in the responses of students in this study that had not yet taken an astronomy course, the instruction students received in both the traditional and transformed courses seems to have successfully facilitated their attainment of a more expertlike understanding of what a scientific theory is.

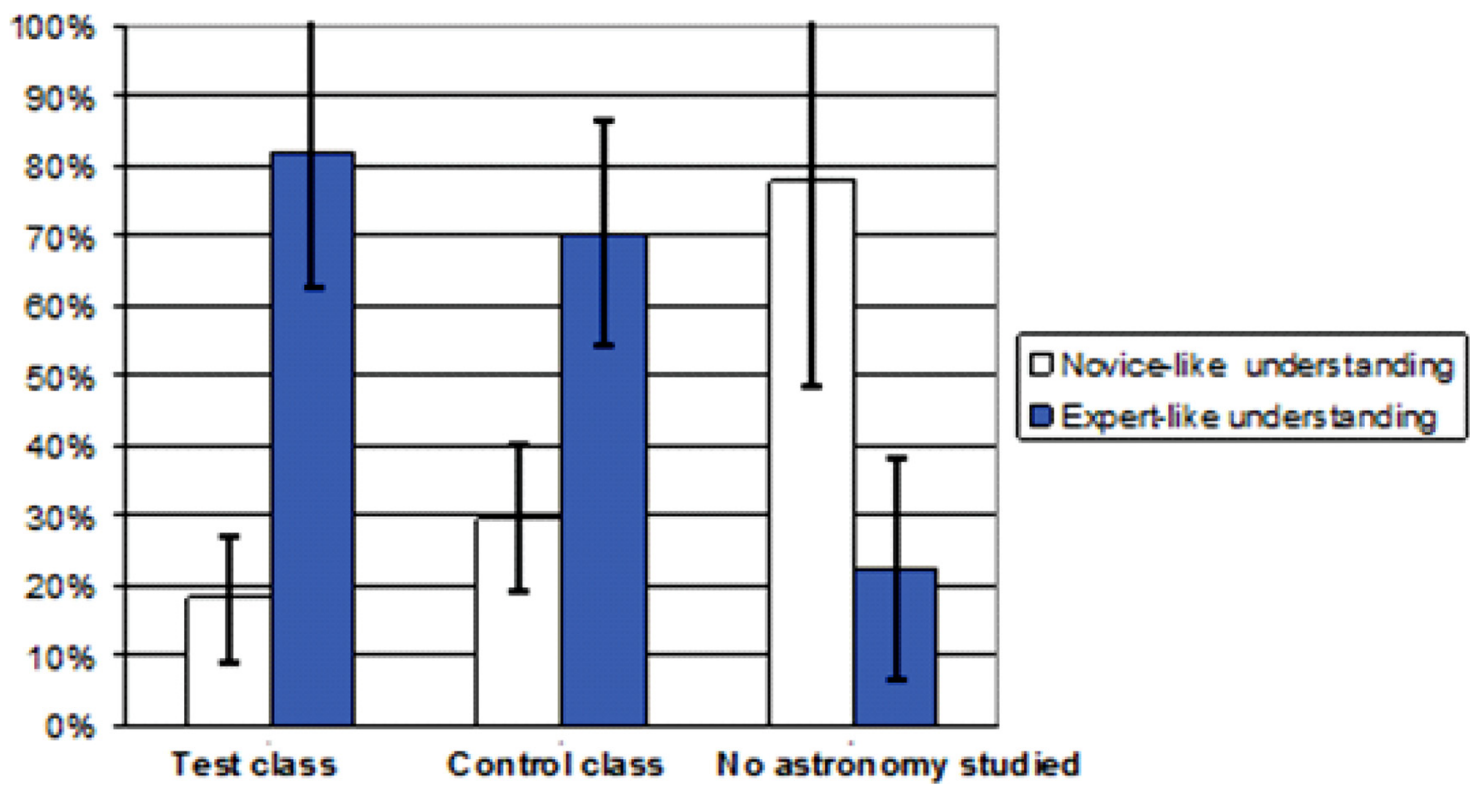

Figure 4. Students in the first week of astronomy instruction ("No astronomy studied") misunderstand the use of the word "theory" when speaking of scientific theories. 
Table 2. Number of students in the control and test classes associated with each type of response. The type of response represents a category of student responses, not the actual students' wording. Table represents data derived from a subset of 116 students from both the Control and Test classes.

Type of response Control

Test

I learned about pseudoscience or can distinguish

pseudoscience from science.

1

I question the credibility of information more, can

find credible sources of information, and am able to

make more educated decisions (and be less fooled by

scams).

I learned a lot about astronomy topics and now I notice these things more in my surroundings and environment (e.g., phases of the moon, shadows, etc.).

I might/will learn more about astronomy either on my own (e.g., google, reading books, etc.) or by taking a class.

I changed my views about the nature of science (e.g., what we know changes over time, astronomy is more than just memorizing facts, etc.).

\subsection{Final Exam Question}

A final assessment of students' views about science in both the Control Class and the Test Class comes from a question asked on the final. The final question of the final exam was, "Has this class changed the way you think about science? If so, how?" A small amount of credit was given for any answer. From each class, we randomly selected 116 student responses to review, bin (i.e., sort), and code. During the initial binning process, 19 different categories emerged. A 19-category coding rubric was then used by two independent coders to code the student responses. It is worth noting that the students' open-ended responses were such that one student could give a response with a variety of comments that fell under different categories within the rubric. Intercoder reliability was greater than $95 \%$ and all initial disagreements were resolved through discussion. We summarize key findings in Table 2.

It is worth noting that, as with the interview and EBAPS data, the student responses to the open-ended final exam question are self-reported perceptions and we did not have a means of verifying their accuracy in the students' actual day-to-day lives.

The most notable differences between student responses from the Test Class versus the Control Class deal with (i) the ability to distinguish pseudoscience from science and (ii) the ability to be more critical or skeptical about information and to make better informed decisions. These findings are undoubtedly a consequence of the embedded NOS curriculum used in the transformed course.

Another notable difference is visible in the higher number of students from the Control Class who explicitly mentioned learning about one or more specific astronomy topics and being more aware of them in their environment. Recalling that the student responses were free writes to an open-ended question, it is possible that although students from the Test Class also learned many astronomy topics (as evidenced by their exam scores; both classes averaged B-grades, their new knowledge of pseudoscience and the abilities they acquired through the embedded curriculum were much more at the forefront of their minds and therefore possibly overshadowed specific astronomy content that they learned.

A third difference is in the almost double the number of students from the Control Class who claimed that they would/might continue to learn more about astronomy either independently or by enrolling in another course. In this regard, one must remember that the Control Class was the first course of a 2-course sequence that satisfies the core science requirement and the Test Class was the second course in such a sequence. In fact, many students from the Control Class said that they intended to take the second course in the sequence to satisfy the core science requirement. 
A final comparison in this particular data set shows that similar numbers of students shared comments that expressed how their views on the nature of science had changed. These comments related to, for example, how they now know that scientific knowledge changes with time, that physics is intimately connected to astronomy, that astronomy is more complicated than originally perceived, etc. This finding is perhaps surprising in light of the goals for the embedded curriculum. However, the embedded NOS curriculum did not address these aspects of science as consistently and with as much focus as it did with goal \#3 (stated under Section 2.1) and it is likely that these findings are a reflection of this difference within the curriculum itself.

\section{CONCLUSION}

The addition of this embedded curriculum to the transformed astronomy course provided students regular opportunities to practice thinking, reading, writing, and talking about genuine science, pseudoscience, and how they learn science. Students from the transformed astronomy course showed significant differences in their ideas about NOS when compared with students from the traditional astronomy course. We were able to distill three major differences using the EBAPS, student interviews, and a final exam question.

The 6 EBAPS items that showed differences between the Test and Control classes were not a random subset of the 30 EBAPS items. In particular, five of the items related to the question of "Who can do science?" The differences in responses between the two classes were large, and all support our first important finding:

Overall, students in the Test Class believed that anyone can do science if they work at it, whereas many more students in the Control Class believed that one must have natural ability in order to do science.

The sixth EBAPS item that showed a significant difference dealt with the nature of knowing and learning science, particularly the importance of making sense of science. Student responses to this item support our second finding:

Overall, students in the Test Class valued making sense of science as part of their learning experience more than students in the Control Class did.

The combination of survey results and student responses to the unprompted essay question at the end of the final exam lead to our third finding:

The strategy of giving students practice distinguishing valid science and pseudoscience in applications outside of the introductory astronomy class leads them to self-report more confidence in their ability to distinguish valid science from pseudoscience, and that they are more likely to think critically in their own lives.

As the National Science Standards suggest, “...in order to participate effectively in a democracy, citizens must understand the nature of scientific claims that increasingly influence or even become matters of public debate (1996)." They must also be willing to participate. The present investigation suggests that explicit instruction of NOS and regular practice enhances this important outcome.

We plan to use the results of this study to develop a survey instrument designed specifically for use in introductory level astronomy courses to evaluate the effectiveness of instruction on students as well as their attitudes and beliefs about science through a Collaboration of Astronomy Teaching Scholars (CATS) research project.

\section{Acknowledgments}

We would like to thank the NSF for funding under Grant No. 0715517, a CCLI Phase III Grant for the Collaboration of Astronomy Teaching Scholars (CATS) Program. Also, we thank the CU Science Education Initiative for its support of this study. We thank the reviewers for their valuable comments and suggestions. Last, but not least, we thank Seth Hornstein and all the students involved in this study.

\section{References}

Abd-El-Khalick, F., Waters, M., and Le, A.-P. 2008, "Representations of Nature of Science in High School Chemistry Textbooks Over the Past Four Decades," Journal of Research in Science Teaching, 45(7), 835. 
Adams, W. K., Perkins, K. K., Podolefsky, N. S., Dubson, M., Finkelstein, N. D., and Wieman, C. E. 2006, "New Instrument for Measuring Student Beliefs About Physics and Learning Physics: The Colorado Learning Attitudes About Science Survey," Phys. Rev. ST Phys. Educ. Res., 2, 010101.

Bao, L., Cai, T., Koenig, K., Fang, K., Han, J., Wang, J., Quing, L., Ding, L., Cui, L., Luo, Y., Wang, Y., Li, L., and Wu, N. 2009, "Learning and Scientific Reasoning," Science, 323(5914), 586.

Clough, M. P. 1997, “Strategies and Activities for Initiating and Maintaining Pressure on Students' Naïve Views Concerning the Nature of Science," Interchange, 28(2-3), 191.

Clough, M. P., and Olson, J. K. 2004, “The Nature of Science Always Part of the Science Story,” The Science Teacher, 71(9), 28.

Epistemological Beliefs Assessment for Physics Science (EBAPS) home page. http://www2.physics.umd.edu/ elby/EBAPS/home.htm, 09/27/2007.

Elby, A., Frederiksen, J., Schwarz, C., and White, B. 2001, “The Epistemological Beliefs Assessment for Physical Science," www.flagguide.org.

Lederman, N. G. 1992, "Students' and Teachers' Conceptions of the Nature of Science: A Review of the Research," Journal of Research in Science Teaching, 29(4), 331.

Lederman, N. G., Abd-El-Khalick, F., Bell, R. L., and Schwartz, R. 2002. "Views of Nature of Science Questionnaire: Toward Valid and Meaningful Assessment of Learner's Conceptions of Nature of Science," Journal of Research in Science Teaching, 39(6), 497.

McComas, W. F. 2004, “Keys to Teaching the Nature of Science,” The Science Teacher, 71(9), 24.

Michaels, E., and Bell, R. 2003, “The Nature of Science and Perceptual Frameworks,” The Science Teacher, $70(8), 36$.

Miller, J. D., 1989, "Scientific literacy," in Paper presented at the Annual Meeting of the American Association for the Advancement of Science (San Francisco, California), 23 p.

Miller, J. D. 1998, “The Measurement of Civic Scientific Literacy,” Public Understanding of Science, 7, 203.

National Committee on Science Education Standards and Assessment, National Research Council, and Center for Science, Mathematics, and Engineering Education, 1996, National Science Education Standards, National Academy Press, Washington, D.C.

Parker, L. C., Krockover, G. H., Lasher-Trap, S., and Eichinger, D. C. 2008, "Ideas About the Nature of Science Held by Undergraduate Atmospheric Science Students," Bulletin of the American Meteorological Society, 89(11), 1681.

Sandoval, W. A. 2003, “The Inquiry Paradox: Why Doing Science Doesn't Necessarily Change Ideas About Science," in Proceedings of the Sixth International Computer-Based Learning in Science Conference, eds. C. P. Constantinou and Z. C. Zacharia, 825.

Slater, T., Adams, J. P., Brissenden, G., and Duncan, D. K. 2001, The Physics Teacher, 31, 8.

Stempien, J. 2007, private communication.

ER

010102-1-010102-11 